\title{
Ensino híbrido e ambiente virtual de aprendizagem na aula de inglês: a perspectiva de alunos do ensino médio técnico
}

\author{
Hybrid learning and virtual learning environment in English \\ classes: the perspective of technical high school students
}

\section{Entorno híbrido de enseñanza y aprendizaje virtual en el aula de inglés: desde la perspectiva de los estudiantes de educación técnica}

Thamiris Oliveira de Araujo ${ }^{1}$

Mariana Guedes Bartolo² https://orcid.org/0000-0002-4217-8531

https://orcid.org/0000-0001-5606-217X

\begin{abstract}
RESUMO: Esta pesquisa busca criar inteligibilidade sobre a introdução de um ensino híbrido da língua inglesa no contexto do ensino médio técnico de uma escola pública. A proposta pedagógica incluiu a realização de exercícios diários em aplicativos educacionais e de tarefas específicas para revisão e aprofundamento de conteúdo das aulas postadas periodicamente em um ambiente virtual de aprendizagem. Assim, a fundamentação teórica inclui os seguintes temas: ensino híbrido (BACICH; MORAN, 2015; GARRIDO, 2009; GEBRAN, 2009; MORAN, 2015), ambientes virtuais de aprendizagem (DILLENBOURG; SCHNEIDER; SYNTEKA, 2002) e learning management system (BERKING; GALLAGHER, 2016). Com o objetivo de investigar a utilização e avaliação dos recursos on-line integrados à disciplina a partir da perspectiva dos alunos, foi conduzido um estudo de caso de natureza etnográfica (ANGROSINO, 2005; HARRIS, 2008; YIN, 2009), contando com entrevistas presenciais e registros dos conteúdos (atividades e recursos) do ambiente virtual de aprendizagem para a geração de dados. Os resultados indicam que os estudantes avaliam o ensino híbrido positivamente, mas privilegiam efetuar as tarefas postadas no ambiente virtual e não as tarefas diárias dos aplicativos educacionais.
\end{abstract}

PALAVRAS-CHAVE: Ensino híbrido. Ambiente virtual de aprendizagem. Aplicativos educacionais.

ABSTRACT: This research aims to create intelligibility on the introduction of hybrid learning in the teaching of English at a public technical high school. The pedagogical proposal included daily exercises on educational applications and some specific tasks to review and deepen the content

\footnotetext{
${ }^{1}$ Doutora em Linguística Aplicada (UFRJ) e professora do Instituto Federal Fluminense (IFF). E-mail: thamirisss.araujo@gmail.com

2 Mestre em Linguística Aplicada (UFRJ). E-mail: marianabartolo@gmail.com
} 
ARAÚJO, T. O.; BARTOLO, M. G.

posted periodically on a virtual learning environment. Thus, the theoretical foundation covers the following themes: hybrid teaching (BACICH; MORAN, 2015; GARRIDO, 2009; GEBRAN, 2009; MORAN, 2015), virtual learning environments (DILLENBOURG; SCHNEIDER; SYNTEKA, 2002) and learning management system (BERKING; GALLAGHER, 2016). In order to investigate the use and evaluation of online resources integrated to the discipline from students' perspective, an ethnographic case study was conducted (ANGROSINO, 2005; HARRIS, 2008; YIN, 2009) based on the data generated by face-to-face interviews and content registration (activities and resources) from the virtual learning environment. The results indicate students evaluate hybrid teaching positively but prefer to do the tasks posted on the virtual learning environment rather than the daily exercises on educational applications.

KEYWORDS: Hybrid learning. Virtual learning environment. Educational applications.

RESUMEN: Esta investigación busca crear inteligibilidad sobre la introducción de la enseñanza del inglés híbrido fuera del contexto del entorno técnico de una escuela pública. Una finalidad pedagógica incluye la realización de ejercicios diarios en aplicaciones educativas y tareas específicas para revisar y profundizar el contenido de las clases publicadas periódicamente en un entorno de aprendizaje virtual. Así, una base teórica comprende los siguientes temas: enseñanza híbrida (BACICH; MORAN, 2015; GARRIDO, 2009; GEBRAN, 2009; MORAN, 2015), entornos de aprendizaje virtuosos (DILLENBOURG; SCHNEIDER; SYNTEKA, 2002) y aprendizaje de sistemas de gestión (BERKING ; GALLAGHER, 2016). Con el fin de investigar el uso y evaluación de dos recursos en línea integrados a la disciplina desde la perspectiva de dos estudiantes, se realizó un estudio de caso de carácter etnográfico (ANGROSINO, 2005; HARRIS, 2008; YIN, 2009), con entrevistas Usted presenciar y registrar dos contenidos (actividades y recursos) del entorno virtual de aprendizaje para la gestión de datos. Los resultados indican que los estudiantes validan positivamente la enseñanza híbrida, que es más privilegiada para realizar tareas publicadas en el entorno virtual en la vida diaria de dos aplicaciones educativas.

PALABRAS CLAVE: Enseñanza híbrida. Ambiente de aprendizaje virtual. Aplicaciones educativas.

\section{Introdução}

As Tecnologias Digitais de Informação e Comunicação (TDICs) avançam a cada dia, transformando o modo como interagimos no mundo. A Internet e os aparelhos eletrônicos, por exemplo, modificaram - e ainda modificam - significativamente nossa relação com o tempo e o espaço. Tais mudanças podem ser percebidas em todas as esferas sociais, inclusive na educacional. Hoje, é bastante comum nos depararmos com cursos na modalidade EaD (Educação a Distância) ou que utilizam alguma ferramenta tecnológica - como softwares para criação de ambientes virtuais de aprendizagem (AVAs) - no decorrer das aulas a fim de flexibilizar o ensino de acordo com o público-alvo.

Tal flexibilização, quando aplicada ao contexto da escola regular, pode ser caracterizada como ensino híbrido, termo que significa "misturado, mesclado, blended" (BACICH; MORAN, 2015, p. 1). Trata-se de uma combinação de diferentes atividades e metodologias que incorporam componentes on-line ao plano de curso de uma disciplina 
oferecida presencialmente. Este caminhar entre o on-line e o off-line que configura 0 ensino híbrido viabiliza a inserção de diferentes estratégias e recursos no processo pedagógico, tendo em vista um aprendizado mais significativo do componente curricular e de outras competências sociais humanas.

Procurando aprimorar o processo de aprendizagem de seus alunos, uma das autoras deste artigo aderiu ao ensino híbrido, ou seja, incorporou componentes on-line em suas turmas presenciais do ensino médio técnico de uma escola pública. Além de utilizar um Learning Management System (LMS) para a criação de um ambiente virtual de aprendizagem (AVA), ela também fez uso de aplicativos educacionais para delegar tarefas diárias complementares às aulas presenciais ao longo do ano letivo de 2018.

Com o objetivo de criar inteligibilidade sobre essa experiência de introdução do ensino híbrido no contexto do ensino médio técnico e de ter acesso à perspectiva dos alunos, conduzimos um estudo de caso de natureza etnográfica (ANGROSINO, 2005; HARRIS, 2008; YIN, 2009). Nele, busca-se responder às seguintes perguntas norteadoras:

1. Como os alunos utilizam o ambiente virtual de aprendizagem e os aplicativos educacionais ao longo de um ano letivo?

2. Como os alunos avaliam o componente on-line da disciplina?

Visando elucidar as perguntas acima, dois instrumentos foram aplicados para promover a geração de dados - registros dos conteúdos (atividades e recursos) do AVA criado e entrevistas presenciais com os alunos em grupos focais. Partindo dos dados, núcleos de significados emergiram (BARDIN, 2009), possibilitando uma análise interpretativa de assuntos correspondentes ao ensino híbrido. Na próxima seção, apresentaremos a base teórica de nosso trabalho.

\section{Ensino híbrido: conceitos e implementação}

O conceito de ensino híbrido é, ao mesmo tempo, rico, apropriado e complicado (MORAN, 2015). A riqueza se refere às infinitas possibilidades de combinações que essa abordagem pedagógica permite e, consequentemente, à diversidade de resultados que obtemos através dessas misturas. Como o mundo está em constante mudança - processo esse que ocorre cada vez mais rápido, por sinal -, essa variedade trazida pelas mesclas 
de diferentes tecnologias digitais, estratégias, metodologias e espaços pode ser uma maneira de acompanhar tais transformações, evitando que a prática docente se torne anacrônica. Por isso, pode-se dizer que o ensino híbrido é apropriado para o momento em que vivemos, apesar da complexidade que ele guarda.

É complicado, em meio a tantas opções, escolher o que se deve incluir ou não nessa mistura, ou seja, decidir "o que vale a pena aprender, para que e como fazê-lo" (MORAN, 2015, p. 27) de acordo com o contexto sociocultural de cada turma. Por isso, é imprescindível elaborar um planejamento pedagógico com base nas necessidades dos aprendizes e nos objetivos que almejam alcançar. Isso nos ajudará não só na seleção e organização dos conteúdos e das experiências de aprendizagem, mas também na determinação do que devemos analisar e de como o faremos (GARRIDO, 2009). Claro que um planejamento como esse exige de nós, professores, uma postura mais ativa e crítica, que nos faz repensar o ensino tradicional - centralizado na sala de aula e no professor -, pois o foco deixa de ser na figura docente e no espaço cercado pelos muros da escola e se redireciona para os alunos e para outros espaços além dela - inclusive o virtual.

Ao mudarmos o foco, dando destaque às bagagens e necessidades dos aprendizes bem como a fatores externos ao ambiente escolar, percebemos como é importante personalizar o modo de ensinar. Através dessas misturas, ou seja, da hibridização de diferentes estratégias, metodologias e espaços, o professor consegue aproximar o conteúdo curricular da realidade dos alunos, atendendo melhor seus objetivos. Isso, além de despertar o interesse da turma, torna a aprendizagem mais significativa.

Com essa mudança de foco, uma nova postura por parte dos alunos, mais participativa e comprometida com a própria aprendizagem, também se faz necessária. Há tempos acostumados a receber conteúdos prontos do professor, esses discentes precisarão aprender a construir saberes junto com ele e os demais colegas, ora estando na posição de quem ensina, ora na de quem aprende. Como não há papéis fixos nesse processo de construção conjunta, pode-se dizer, então, que, tal qual o ensino, eles também são híbridos.

Por requerer uma postura mais ativa tanto dos professores quanto dos aprendizes e uma troca constante, o ensino híbrido estimula não só o desenvolvimento da autonomia, mas também a interação entre os envolvidos. Ao perceber que sua 
contribuição é essencial para que o processo de ensino-aprendizagem tenha continuidade, o aluno, na maioria das vezes, se sentirá mais motivado a participar, compartilhando o que sabe e construindo novos saberes a partir do que é trazido pelo outro. Essa construção ressignifica seus conhecimentos, facilitando a resolução de tarefas quando não há por perto um par mais experiente (VYGOTSKY, 1999) e, consequentemente, aumentando sua autonomia.

Outro benefício trazido pela adoção do ensino híbrido, principalmente quando é aliado à utilização de tecnologias digitais, é a possibilidade de adaptação do ritmo de estudo. Mais flexível e personalizada, nessa abordagem pedagógica o aprendizado pode acontecer em qualquer hora e em qualquer lugar, não só no momento em que se está na sala de aula. Com essa flexibilidade de horários e espaços, o aprendiz consegue adaptar melhor os estudos a sua rotina e a seus objetivos.

Algumas pessoas, no entanto, não conseguem lidar muito bem com essa liberdade de escolha que flexibiliza o processo de ensino-aprendizagem e acabam não se engajando de forma significativa nas atividades. Isso acontece porque, ao longo da vida escolar, houve pouco ou nenhum encorajamento para que elas desenvolvessem sua autonomia e se tornassem protagonistas do próprio aprendizado. Tendo em vista essa dificuldade trazida por um grande número de aprendizes, aderir ao ensino híbrido de maneira mais ampla, com mudanças profundas (BACICH; MORAN, 2015) não é a melhor escolha. Para que haja um maior engajamento por parte dos alunos, é preciso fazê-lo de forma mais suave e gradual.

De acordo com Bacich e Moran (2015), nessa maneira mais suave, o modelo curricular tradicional baseado em disciplinas é mantido enquanto o foco se volta para o planejamento de atividades que envolvam os alunos tanto no processo de ensinoaprendizagem quanto na troca com os outros colegas. Para que isso aconteça, são utilizadas estratégias como as metodologias ativas na realização de projetos e de jogos individuais ou em grupo, de modo colaborativo. Muitas vezes, atividades desse tipo incluem o uso de tecnologias digitais em algum momento, integrando o presencial com o virtual.

Na disciplina alvo desta pesquisa, por exemplo, dentre as tecnologias digitais listadas anteriormente, são utilizados um software educacional e aplicativos que possuem 
interfaces de jogos educacionais para hibridizar o processo de ensino-aprendizagem. Por ser uma disciplina presencial, a professora regente procura inovar e estimular a interação e o envolvimento dos alunos através do uso de tecnologias digitais, mais especificamente, de um Learning Management System (LMS) gratuito e disponível para acesso por site e aplicativo para dispositivos móveis. Além de utilizar as ferramentas provenientes deste software, a docente utiliza recursos da Internet para compor o ambiente virtual de aprendizagem (AVA). A seguir, essas duas nomenclaturas são definidas.

\section{O LMS e a criação de AVAs}

Chama-se de LMS, sigla para Learning Management System (em português, sistema de gerenciamento de aprendizagem), qualquer software que ofereça estrutura e recursos para a construção de um ambiente educacional on-line. Moodle, Edmodo, Google Classroom e Blackboard são alguns exemplos de plataformas populares desse tipo. Através de sua utilização, os professores conseguem criar e gerenciar conteúdos e atividades, bem como acompanhar o desempenho dos aprendizes.

Além da estrutura, que permite a centralização e organização do sistema, um LMS pode apresentar muitas outras funções (Figura 1). De acordo com Berking e Gallagher (2016), sistemas de gerenciamento também oferecem personalização, atendendo a necessidades específicas dos usuários; segurança, impedindo acessos não autorizados; inscrição, distribuindo alunos e professores de acordo com os cursos; integração, possibilitando a troca de dados com sistemas externos; interação, permitindo a comunicação entre os usuários inscritos e a interação com o conteúdo; distribuição, viabilizando a disponibilização de conteúdo sob demanda; relatórios, possibilitando a extração e apresentação de informações sobre os alunos; reutilização de conteúdo, reaproveitando o ambiente criado na construção de novos cursos; armazenamento de registros, guardando todas as trocas de mensagens, atividades e conteúdos disponibilizados; avaliação, coletando e rastreando dados para avaliação; e controle, armazenando os dados dos alunos. Para gerenciar todas elas, é preciso que haja uma administração centralizada. 
Figura 1 - LMS: funções

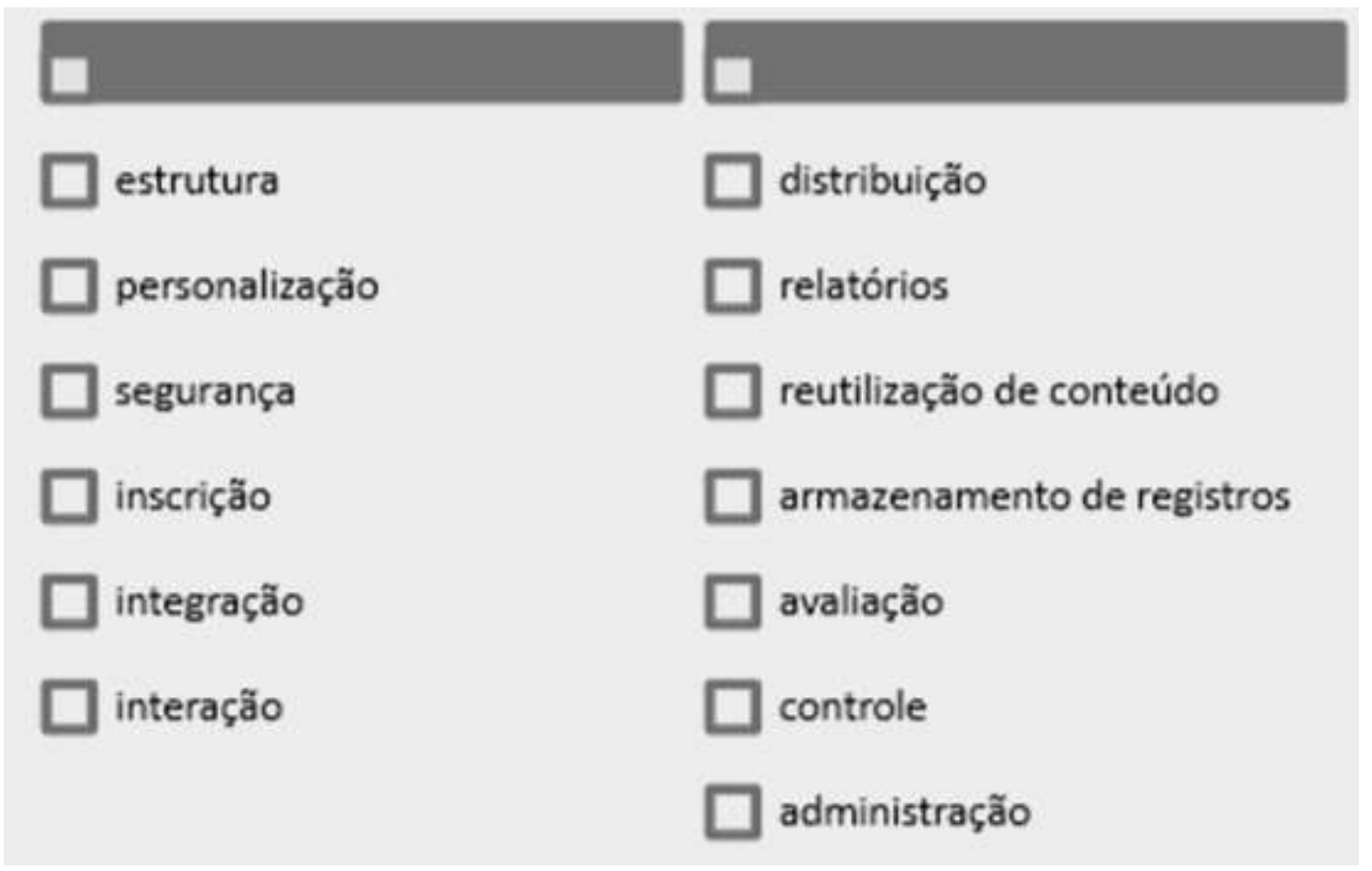

Fonte: Adaptado de Berking e Gallagher (2016)

Essa diversidade de funções, como apontam Dillenbourg, Schneider e Synteka (2002), é o que torna possível a adoção de diferentes abordagens de ensino bem como o uso pedagógico e integrado dos recursos disponibilizados, favorecendo a interação entre os participantes. Entretanto, a forma como tais interações irão ocorrer dependerá das ferramentas e funções do LMS selecionadas pelo professor. Ao escolher tais recursos, o docente começa a construir o ambiente virtual de aprendizagem (AVA) do curso em questão. Segundo Dillenbourg, Schneider e Synteka (2002), esses AVAs possuem como características gerais:

- $\quad$ O planejamento do ambiente para que ocorram interações entre os envolvidos;

- A possibilidade de construção através de linguagens simples, exclusivamente em texto, ou de sofisticados recursos multimidiáticos para elaboração de ambientes imersivos;

- $\quad$ A participação ativa dos aprendizes, tanto nas atividades propostas quanto na co-construção dos ambientes virtuais em que estão inseridos;

- $\quad$ A possibilidade de utilização não só na modalidade a distância, mas também na presencial, como uma forma de complementar as aulas;

- A possibilidade de integração de tecnologias heterogêneas e de 
múltiplas abordagens pedagógicas.

Esses ambientes virtuais podem ser criados através de diversas plataformas, inclusive em aplicativos de celular que não foram projetados para fins educacionais, como o WhatsApp. Contudo, ao utilizarmos um LMS para criá-lo, temos como vantagens as funções descritas anteriormente e as ferramentas disponibilizadas no sistema para o aprimoramento da experiência de aprendizagem.

A seguir, além de definirmos a natureza desta pesquisa, traçamos os objetivos e comentamos sobre os instrumentos utilizados para gerar dados.

\section{Metodologia}

Esta pesquisa busca compreender a forma como alunos do ensino médio técnico utilizam e avaliam os recursos on-line integrados à disciplina de língua inglesa - o uso de um ambiente virtual de aprendizagem (AVA) e a utilização regular de aplicativos educacionais para a realização de tarefas complementares às aulas presenciais. Como tal objetivo está relacionado a aspectos comportamentais, não traduzíveis em números, localizamos o presente estudo dentro do paradigma qualitativo. Este paradigma possibilita a consideração de aspectos sociais que atravessam as questões investigadas, assim como a adoção de uma postura interpretativa diante do contexto estudado, uma vez que reconhece "a natureza socialmente construída da realidade, a estreita relação entre o pesquisador e o contexto da pesquisa e as limitações situacionais que influenciam a pesquisa" (DENZIN; LINCOLN, 2006, p. 23). Logo, em estudos como o nosso, os pesquisadores não isolam o fenômeno investigado nem se isolam dele.

Por privilegiarmos o ponto de vista de um grupo específico de indivíduos - turmas de ensino médio técnico de uma escola pública - em nossa investigação, compreendendo o fenômeno a partir da perspectiva dos participantes, optamos por conduzir um estudo de caso de natureza etnográfica (ANGROSINO, 2005; YIN, 2009). De acordo com Harris (2008), essa abordagem é recomendada quando interação e engajamento são aspectos ligados ao objetivo da pesquisa.

O contexto - uma escola pública onde uma das autoras atua como professora de inglês como língua estrangeira - foi investigado ao longo do ano letivo de 2018. Participaram da pesquisa quatro turmas de um curso técnico em edificações - integrado 
ao ensino médio técnico, sendo duas turmas do primeiro ano e duas do terceiro ano, somando cerca de 110 alunos com idades entre 15 e 20 anos. 0 currículo escolar inclui duas aulas de inglês de 50 minutos por semana e as turmas são notavelmente heterogêneas em termos de proficiência linguística. Havia, durante o ano de 2018, um laboratório de informática que funcionava todas as tardes, assegurando que os alunos que não possuíam acesso à Internet em casa ou em seus celulares realizassem as tarefas propostas na própria escola.

É importante ressaltar que a investigação foi desenvolvida após a obtenção de uma autorização da instituição. Além disso, todos os alunos integrantes das quatro turmas participantes da pesquisa receberam um termo de consentimento livre e esclarecido, que foi assinado pelos alunos maiores de idade e pelos responsáveis dos alunos menores de idade. No termo, foram elucidados os objetivos da pesquisa, assim como sua relevância para a aprendizagem da língua inglesa. Ademais, o termo enfatizava que a não participação do aluno como voluntário da pesquisa ou a descontinuação de tal participação em um momento futuro poderia ocorrer sem penalização alguma e sem prejuízo de qualquer natureza. Foi destacado também que a participação na pesquisa não geraria custos para o aluno em virtude dos sites/aplicativos selecionados serem gratuitos.

Nesta pesquisa, foram utilizados dois instrumentos para promover a geração de dados aqui apresentada: registros dos conteúdos (atividades e recursos) do AVA e entrevistas presenciais. Como não foi possível entrevistar todos os alunos, a docente convidou alguns deles para participar de entrevistas em grupos focais, contando com três ou quatro alunos por grupo. Os alunos foram informados previamente que a entrevista seria gravada e que a participação era opcional. No final do ano letivo, 19 alunos foram entrevistados.

A interpretação dos dados se baseou na análise de conteúdo (BARDIN, 2009), abrangendo as diferentes fases de análise: pré-análise, exploração do material e tratamento dos resultados, inferência e interpretação. O processo de categorização envolveu a identificação de núcleos de significados a partir da investigação do campo semântico-lexical, seguido da criação de categorias de análise correspondentes ao ensino híbrido, conforme exposto a seguir. 
ARAÚJO, T. O.; BARTOLO, M. G.

\section{Análise}

Nesta seção, apresentamos um detalhamento sobre o percurso da pesquisa, assim como a análise dos dados concernentes à utilização e avaliação dos recursos on-line que integram a hibridização do ensino da língua inglesa na perspectiva dos estudantes. Esta pesquisa se iniciou quando, ao elaborar seu planejamento de curso, a professora de língua inglesa em questão resolveu acrescentar o componente on-line de forma regular em suas aulas. Após investigar possíveis softwares para criar o AVA das turmas, ela optou pelo Edmodo, por se tratar de um LMS gratuito de utilização intuitiva que facilita a comunicação entre docente e alunos.

No primeiro dia letivo, a professora realizou uma sondagem para descobrir com quais turmas seria viável trabalhar com o ensino híbrido. Um breve questionário diagnóstico foi aplicado para investigar as possibilidades de acesso, a familiaridade e a motivação dos estudantes para realizar tarefas em aplicativos educacionais. Ao ler as respostas, foi descoberto que a maioria dos alunos possuía smartphones com Internet móvel e/ou Internet Wi-Fiem suas residências. Muitos deles, inclusive, já haviam utilizado aplicativos, como o Duolingo, e demonstraram entusiasmo em trocar as tradicionais tarefas de casa em folhas ou no livro por exercícios on-line. Com base nos resultados do diagnóstico, a docente iniciou o trabalho com as turmas explicando o que era um AVA e orientando os participantes a criarem o login através do site ou aplicativo do Edmodo para que, depois, fosse possível adicionar em suas contas a senha para ingresso na turma virtual.

No Edmodo, os alunos tiveram acesso à proposta de realizar exercícios contínuos em aplicativos educacionais. As turmas de $1^{\circ}$ ano utilizaram o Duolingo e as de $3^{\circ}$ ano utilizaram o Memrise. Ambos são gratuitos, gamificados, solicitam uma dedicação diária de somente cinco minutos e possibilitam a criação de turmas para acompanhamento do professor das tarefas realizadas pelos alunos. Além desses aplicativos, os alunos também deveriam realizar outras tarefas postadas no Edmodo, que mantinham uma relação direta com a matéria explorada nas aulas presenciais, como: listas de vocabulário de inglês técnico e geral pelo Quizlet, vídeo-aulas selecionadas do Youtube (Figura 2), quizzes para revisão de conteúdo e sites com exercícios gramaticais de correção automática. O Edmodo propicia o que Berking e Gallagher (2016) atribuem à função de integração de 
um LMS, possibilitando a inserção de dados externos, visando explorar outros conteúdos e recursos de aprendizagem.

Figura 2 - Link para playlist do Youtube, compartilhado pelo Edmodo

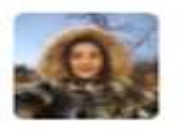

Thamiris Araujo postou para English $3 \mathrm{~A}$

Professor(a) 0 às

nov 27, 2018 - 10:23 PM - 2ls

Tarefa pré-aula: videos VOZ PASSIVA

Entregue (0) Para: novembro 29, 2018, 11:45 pm

$\mathrm{Hi}$, guys! I need you to watch the videos about the passive voice that I uploaded to our playlist BEFORE the class. You can do it in less than 10 minutes! (-)

https://umw. youtube.com/playlist?list=PLaNG8nIUUzPriXNJpHdlolj81LEgQ9rbJ
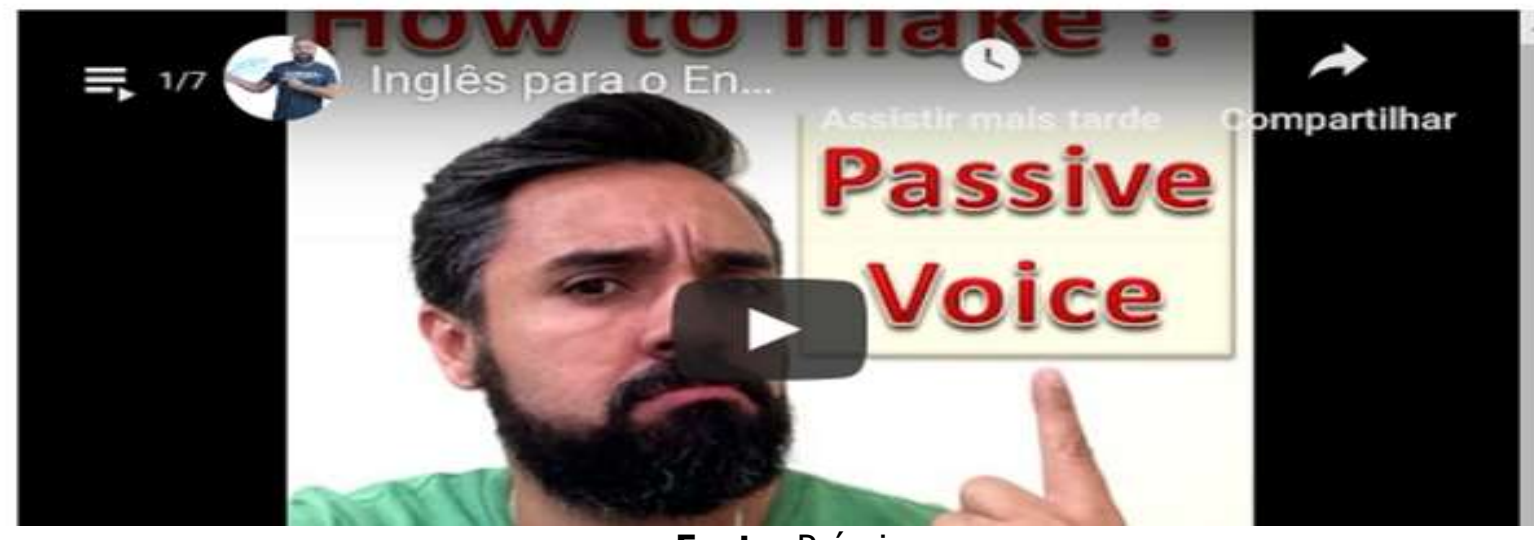

Fonte: Própria

No entanto, ao longo do ano letivo, por vezes os alunos diminuíam consideravelmente a frequência de realização das tarefas on-line. Visando atenuar o fato e incentivar os alunos, ao fim dos primeiros meses, a professora declarou que as tarefas on-line passariam a valer um ponto na média, sendo necessário somente fazê-las com regularidade para alcançar a pontuação. Como tal incentivo não surtiu grandes efeitos, coube à professora lembrar constantemente seus alunos sobre a importância de verificar o AVA e de realizar os exercícios de cinco minutos do aplicativo de uso contínuo.

Ao final do ano letivo, foram realizadas entrevistas em grupos focais, cujo tema inicial foi a frequência na utilização dos recursos on-line. A seguir, apresentamos alguns comentários feitos pelos discentes. É importante ressaltar que os nomes foram trocados para preservar a identidade dos participantes. Nessas entrevistas, o esquecimento de realizar as tarefas foi mencionado por alguns alunos, seja pelo fato de não receber a 
notificação do aplicativo de nova mensagem no celular ("[...] não lembrava que tinha que ver"), como é o caso de James, ou de recebê-la, mas se distrair com o fluxo de interações promovido pelas redes sociais e aplicativos de conversas ("[...] ignorava o Edmodo e ia mexer no WhatsApp'), como é o caso de Larissa.

James - $\mathbf{1 0}^{0}$ ano: Notificação... Eu não baixava o aplicativo porque meu celular tem pouca memória, aí pela Internet eu não recebia notificação do que você posta.

Professora: Mas não chegava no seu e-mail?

James $-1^{\circ}$ ano: Eu também não tenho o e-mail instalado. Não chegava notificação, então eu não lembrava que tinha que ver.

Larissa - $3^{\circ}$ ano: Às vezes aparecia a notificação do Edmodo e a notificação do Whatsapp, aí, tipo, você ignorava o Edmodo e ia mexer no Whatsapp.

As duas perspectivas expostas pelos alunos denotam uma falta de automonitoramento em seus estudos. Apesar de possuírem a rotina de utilizar a Internet para fins de lazer, alguns alunos não desenvolveram o hábito de verificar o aplicativo para realizar a tarefa de inglês da semana. Isso nos surpreendeu, pois, por terem em sua maioria o celular nas mãos e acentuada frequência de uso da Internet, esperávamos que eles se engajassem mais nas atividades on-line. É possível atribuir tal esquecimento a uma avaliação negativa da integração de componentes on-line à disciplina, na medida em que esta gerou uma mudança significativa na cultura escolar dos alunos, se afastando da recomendação de Bacich e Moran (2015) de uma adaptação suave ao ensino híbrido.

Contudo, as falas de muitos alunos remontam a uma dificuldade em lidar com as tarefas complementares também de outras disciplinas, visto que o ensino médio técnico integrado é de horário integral. Devido a essa alegação relacionada à falta de tempo, os alunos lidam com as tarefas complementares ignorando-as ("No caso, quando eu chego em casa, eu esqueço totalmente da escola. Então eu não faço os trabalhos."), esquecendo de fazer algumas delas ("[...] é muita coisa na cabeça e a gente acaba esquecendo de fazer as atividades.") ou selecionando quais tarefas fazer ("[...] dando prioridade a certas matérias."). A fala de Paulo, Ana Julia e Juca demonstram que o acúmulo de tarefas não executadas ocorre tanto nas disciplinas técnicas quanto nas propedêuticas, seja qual for a metodologia aplicada pelo professor. 
Paulo - $\mathbf{1 0}^{0}$ ano: No caso, quando eu chego em casa, eu esqueço totalmente da escola. Então eu não faço os trabalhos. [...] Geografia, eu não fiz nenhum desses deveres que ela passou para casa. Nenhum.

Ana Julia - $1^{\circ}$ ano: Não é devido a ser on-line, acho que é porque é muita coisa na cabeça e a gente acaba se esquecendo de fazer as atividades. Até no caderno eu tenho esquecimento de fazer.

Juca $-3^{\circ}$ ano: Tem a carga horária e a questão de que a gente tem um monte de atividades para fazer além das aulas, então isso acaba acumulando, acumulando e a gente acaba esquecendo, dando prioridade a certas matérias.

Ainda sobre a utilização dos recursos on-line, os alunos mencionaram que possuíam predileções por determinadas tarefas e optavam por fazer as que lhes pareciam mais interessantes ("Para mim, assim, eu fazia as da parte técnica porque eu acho legal [... $]^{\prime \prime}$ ) ou menos cansativas ("Eu só não fiz o Duolingo. Só fiz no $1^{0}$ trimestre porque eu achei muito trabalhoso fazer todo dia cinco minutos."/"Eu só fazia os deveres que eram mais rápidos."). Esta ação, exemplificada nas falas de James, Luis Felipe e Thais coaduna com a função de personalização da aprendizagem possibilitada pelo LMS (BERKING; GALLAGHER, 2016) e com a característica de adoção de múltiplas abordagens pedagógicas potencializadas pelo AVA (DILLENBOURG; SCHNEIDER; SYNTEKA, 2002). Assim, os estudantes ajustaram suas preferências pessoais e necessidades organizacionais para a realização das tarefas complementares.

James $\mathbf{- 1 0}$ ano: Para mim, assim, eu fazia as da parte técnica porque eu acho legal, mas a de matéria de inglês eu acho chato.

Luis Felipe - $\mathbf{1 0}^{\circ}$ ano: Eu só não fiz o Duolingo. Só fiz no $1^{\circ}$ trimestre porque eu achei muito trabalhoso fazer todo dia cinco minutos.

Thais - $3^{\circ}$ ano: Quando terminava a sua aula, eu ficava a parte inteira da tarde no laboratório fazendo os Quizlets, mas o Memrise eu não fazia senão ia ter que tirar muito tempo para fazer. Eu só fazia os deveres que eram mais rápidos.

Quando questionados sobre a acessibilidade aos aplicativos e sites utilizados, as palavras-chaves que emergem dos dados são: "mais acessível", "grátis", "mais prático" e "menos chato". Em geral, os alunos se posicionaram favoravelmente, ressaltando a gratuidade e a dinamicidade das atividades on-line, assuntos enfatizados por Ana Julia e Dalila. Mesmo assim, foram relatadas dificuldades de acesso no $1^{0}$ trimestre devido a 
complicações tecnológicas ou ao esquecimento de realizar o login com adição do código para ingresso no AVA da turma. Quanto a isso, a aluna Naiara apresentou valiosa sugestão de realizar a criação do login com a turma presencialmente ("[...] ia para o laboratório e todo mundo criava o login, aí já desperta mais para todo mundo ficar ciente"). Tal ação talvez pudesse assegurar que um número maior de alunos começasse a usar o AVA desde o início.

Ana Julia - $1^{0}$ ano: Eu acho que fica mais acessível, a pessoa poder entrar e fazer os exercícios. É uma coisa para todo mundo, não é uma coisa restrita. Como você ter que comprar um livro, já é uma coisa que eu acho mais restrita do que você ter um aplicativo grátis no seu celular.

Dalila - $3^{\circ}$ ano: Eu acho que é até mais prático fazer no celular e no computador do que no caderno, é mais dinâmico, acaba sendo menos chato, você olha e tem mais interesse.

Naiara $-3^{\circ}$ ano: No primeiro dia falta muita gente. Eu acho que se fosse, assim, terceira aula, ia para o laboratório e todo mundo criava o login, aí já desperta mais para todo mundo ficar ciente.

Os alunos também teceram avaliações positivas referentes à estrutura propiciada pelo LMS. Segundo Berking e Gallagher (2016), o armazenamento de registros, disponibilizando a qualquer tempo e em um só ambiente o acesso a atividades e conteúdos do curso ministrado, é uma função inerente a tais softwares. Tal função é explicitada por Mariana e Thais, com ênfase na praticidade advinda do uso de um sistema de gerenciamento da aprendizagem ("A gente tinha acesso a todos os exercícios." "Você vê na lista todas as coisas exclusivas daquela matéria"). O Edmodo congrega todas as postagens em uma página inicial denominada feed de acordo com a ordem cronológica dos eventos, privilegiando as postagens mais recentes.

Mariana $-1^{\circ}$ ano: Gostei. Tinha exercício nele, né. A gente tinha acesso a todos os exercícios. Eu achei bem legal porque eu não precisava ir em outro lugar para achar os exercícios, ali achava tudo.

Thais - $3^{\circ}$ ano: Você vê na lista todas as coisas exclusivas daquela matéria para a sua turma.

A função de distribuição (BERKING; GALLAGHER, 2016), que viabiliza a disponibilização de conteúdo, também foi avaliada positivamente pelos estudantes. $O$ Edmodo disponibiliza a postagem de tarefas no feed, sendo possível agendar o período 
em que um exercício ou um trabalho escolar poderá ser enviado. Através do recurso planner (em português, planejamento), temos um calendário mensal com a data de postagem das tarefas (Figura 3). Na própria postagem sobre a tarefa, o aluno realiza a entrega, de forma intuitiva, conforme explicam Thais ("[...] ele abre uma caixinha 'enviar trabalho"') e James ("Outra coisa que facilitava era a entrega de trabalho [...]").

Thais - $3^{\circ}$ ano: Para você enviar um trabalho, ele abre uma caixinha "enviar trabalho".

James - $\mathbf{1}^{0}$ ano: Outra coisa que facilitava era a entrega de trabalho porque aquele aplicativo de áudio [se referindo ao Soundcloud] é muito difícil. Eu não consegui enviar o trabalho nesse site pelo meu celular, consegui pelo Edmodo.

Figura 3 - Calendário de tarefas mensal

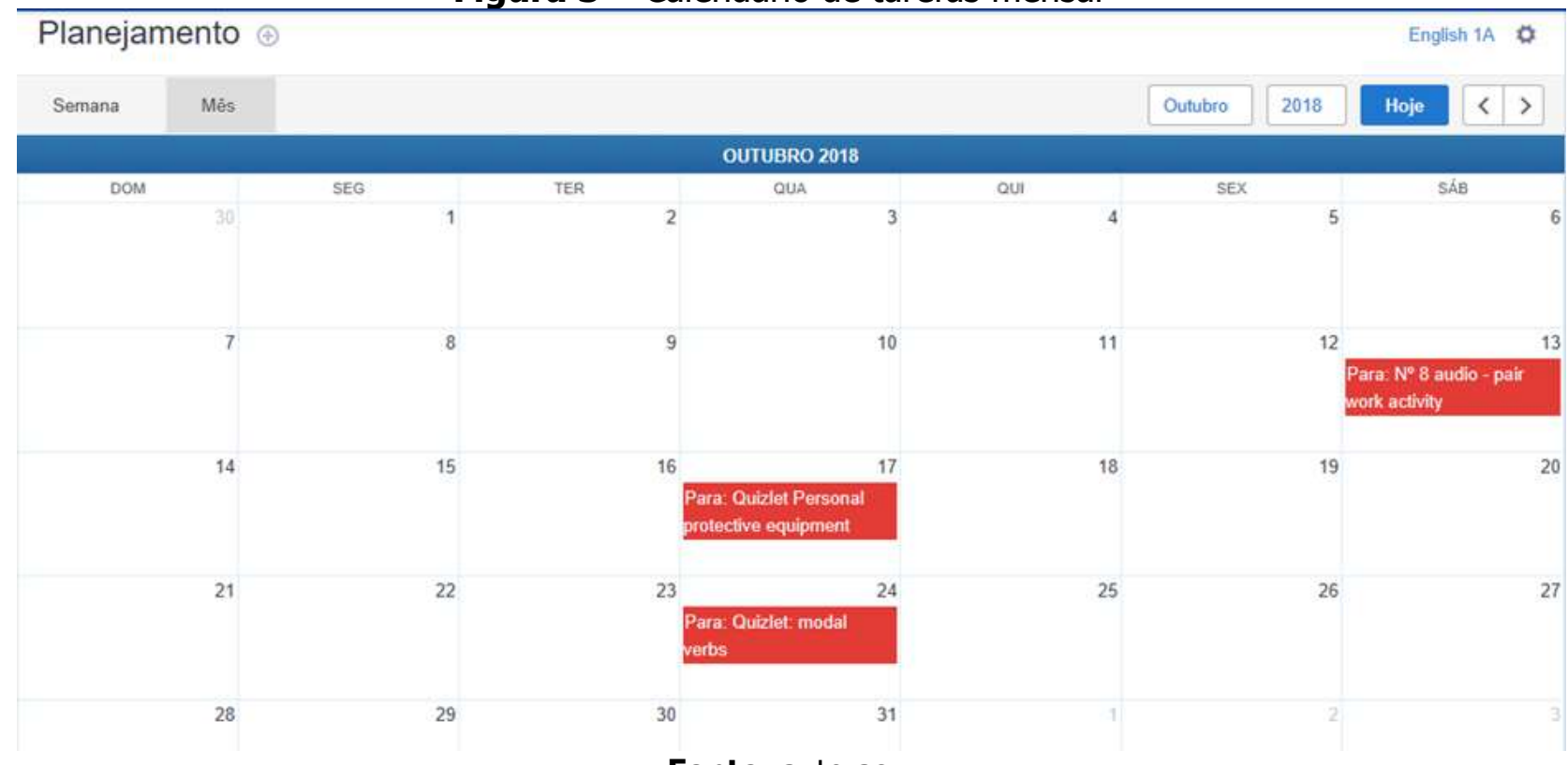

Fonte: autoras

Os alunos também foram solicitados a fazerem uma comparação entre as formas de comunicação professor-aluno fora da sala de aula, avaliando a função de interação do LMS (BERKING; GALLAGHER, 2016). Muitos professores utilizam o e-mail da turma para comunicações, envio de material para estudo e recebimento de trabalhos dos alunos, atividades que, nas aulas de inglês, eram realizadas através do Edmodo. As palavraschave dessa avaliação foram: "mais rápido", "tem a forma de chat, de conversa mesmo" e "parecida com o WhatsApp". Houve consenso ao avaliar positivamente a interação via LMS, visto que o professor tende a responder mais rapidamente e que a comunicação via 
chat se dá de forma mais informal, direta e familiar aos alunos, como apontam Dalila, Isabela e Tito.

Dalila - 10 ano: É muito mais rápido do que você ter que esperar o dia do professor dentro da escola, se surgir uma dúvida. [...] O e-mail você tem que esperar a pessoa entrar, então no Edmodo é mais rápido mesmo.

Isabela - $1^{\circ}$ ano: O Edmodo tem a forma de chat, de conversa mesmo, já o e-mail é mais chatinho para entrar, a pessoa não fica $24 \mathrm{~h}$ no e-mail. Já no Edmodo você recebe notificação.

Tito - $\mathbf{3}^{\circ}$ ano: Ele tem uma forma parecida com o WhatsApp, então fica mais fácil.

Figura 4 - Chat do Edmodo

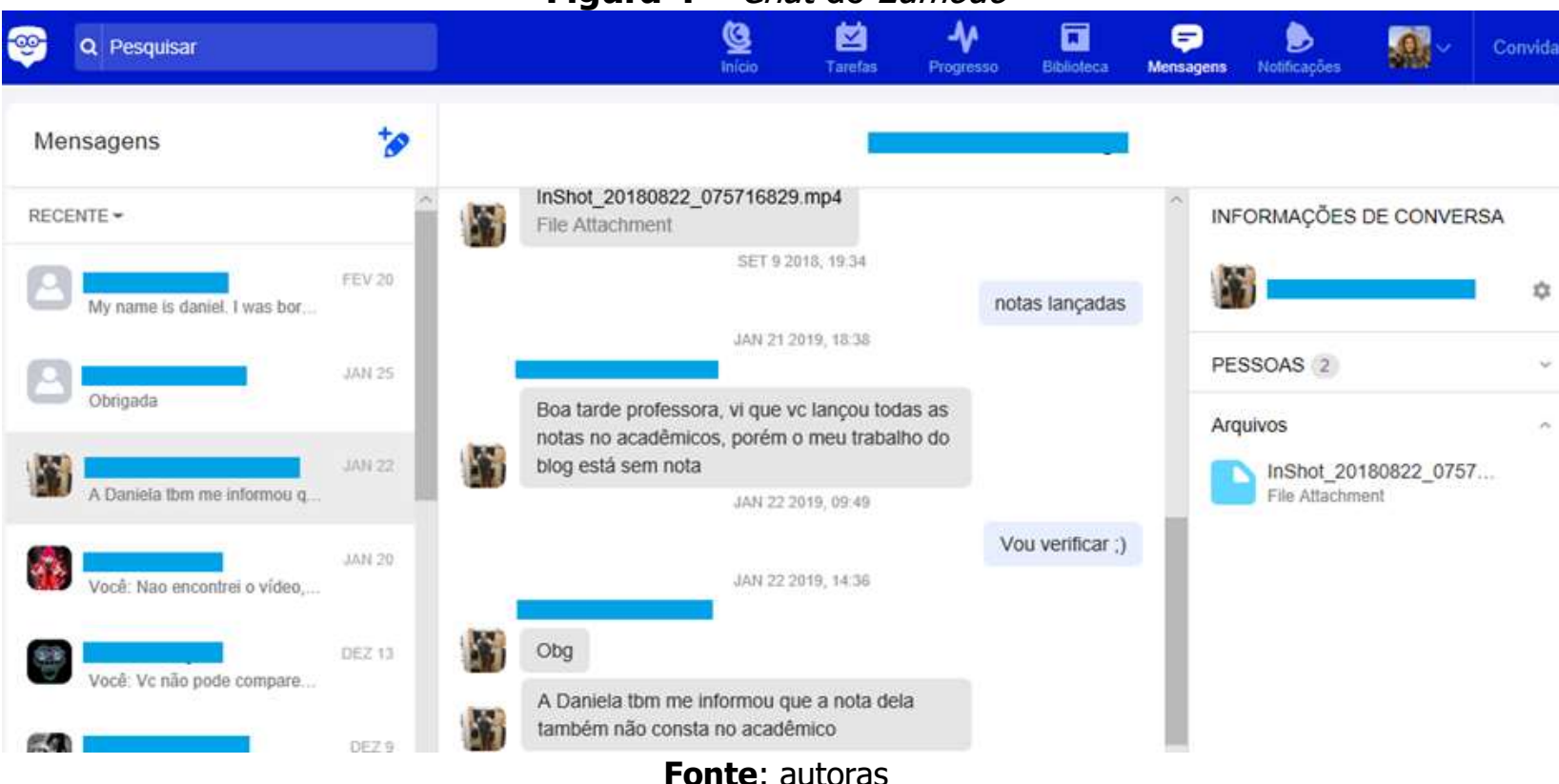

Fonte: autoras

Considerando a avaliação positiva de diversas funções do LMS Edmodo e o fator esquecimento evidenciados em diversas falas, a docente finalizou a entrevista solicitando sugestões de como aprimorar a abordagem do ensino híbrido para o próximo ano letivo. Em todos os grupos focais, a criação de um grupo no aplicativo WhatsApp como estratégia pedagógica foi mencionada. Primeiramente, pela maioria dos alunos já possuir o aplicativo instalado em seus celulares, como exemplifica Leandro. E, em segundo lugar, pelas turmas já terem um grupo específico para tratar de assuntos escolares no aplicativo, grupo este que, durante a entrevista, foi citado como um local em que já ocorre o compartilhamento de informações sobre as tarefas postadas pela professora no Edmodo, conforme explicita Ana. 
Leandro - $\mathbf{1}^{\circ}$ ano: Às vezes a pessoa não tem memória no telefone para baixar o Edmodo, mas o WhatsApp a pessoa vai ter com certeza.

Ana - $3^{\circ}$ ano: A Gisele [representante da turma] sempre fala no grupo "a professora postou uma mensagem no Edmodo", aí a gente vai lá ou ela manda um print.

A vantagem do uso do WhatsApp com as turmas seria aproximar-se dos alunos e manter um diálogo mais direto sobre as tarefas propostas, como resume a fala de Gisele. No entanto, a criação de um grupo de WhatsApp não poderia substituir o AVA, posto que há alunos que não possuem telefone celular e acessam o conteúdo on-line através do site ou que dependem da notificação por e-mail. Além disso, os grupos de WhatsApp não possuem a possibilidade de estruturação de dados oferecidos por um LMS como o Edmodo. No que diz respeito a estes empecilhos, a aluna Celina propõe a utilização das duas plataformas, de forma que uma complemente a outra.

Gisele - $3^{0}$ ano: Eu acho que o WhatsApp vai te trazer maior comunicação com os alunos.

Celina $-3^{\circ}$ ano: WhatsApp é uma ferramenta que tá todo mundo mais acostumado, todo mundo fica mexendo quase o dia inteiro, mas eu acho que uma não necessariamente excluiria a outra. Poderia utilizar o WhatsApp para dar avisos, tipo, "amanhã não vai ter aula" ou então "postei uma tarefa nova no Edmodo". Deixa o Edmodo para coisas mais importantes, para tarefas, coisas que vão ficar organizadinhas, e o WhatsApp para algo mais prático.

A inserção do WhatsApp no ensino híbrido poderia trazer contribuições significativas ao processo pedagógico por se tratar de um aplicativo de frequente utilização por parte dos alunos. Apesar de demandar uma pesquisa específica sobre usos educacionais, a própria proposta de uso deste aplicativo pelos alunos denota que eles estão abertos ao ensino híbrido a ponto de atribuir um viés de educação formal a um espaço que é lócus de lazer e de aprendizagem informal entre seus pares. A seguir, nas considerações finais, refletimos mais um pouco sobre os dados aqui apresentados e sugerimos encaminhamentos.

\section{Conclusão}


O objetivo da presente pesquisa é criar inteligibilidade sobre a introdução de um ensino híbrido da língua inglesa no contexto do ensino médio técnico de uma escola pública a partir da perspectiva dos estudantes. Por isso, o estudo teve como cerne a utilização e avaliação dos recursos on-line integrados à disciplina no período de um ano letivo. A proposta pedagógica incluiu a realização de exercícios contínuos em aplicativos educacionais e de tarefas específicas postadas periodicamente em um ambiente virtual de aprendizagem. Os dados investigados foram gerados através da análise de registros dos conteúdos (atividades e recursos) do AVA e de entrevistas presenciais com os alunos em grupos focais.

No quesito utilização dos aplicativos/sites selecionados, os dados indicam que os estudantes demonstram tendência de se esquecerem das tarefas on-line e que, por isso, precisam de lembretes da professora durante as aulas ou de algum colega de classe através do grupo particular de WhatsApp da turma para que realizem as atividades. Tal esquecimento pode indicar uma falta de tempo, de hábito ou até mesmo de comprometimento real com a disciplina. Santaella (2010, p. 2) comenta que as novas tecnologias alteram as "funções sociais realizadas pelas tecnologias precedentes, provocando remanejamentos no papel que cabe a cada uma desempenhar". Dessa forma, a associação de tecnologias digitais como atividades complementares ao ensino presencial, substituindo deveres de casa de cunho mais tradicional, pode de fato tornar a aprendizagem mais significativa ao expandir a diversidade de recursos pedagógicos, promovendo a colaboração e personalização, mas, se o aluno se sentir sobrecarregado ou não aprender a organizar seus estudos, irá esquecer-se de executar atividades on-line da mesma forma que esqueceria uma atividade no livro didático.

Além disso, alguns estudantes realizavam somente as tarefas que julgavam mais adequadas a seus interesses, necessidades de aprendizagem ou tempo disponível, o que pode ser interpretado como uma estratégia de personalização da experiência de aprendizagem. De maneira geral, os exercícios no Quizlet e as demais tarefas pontuais postadas no Edmodo, que possuíam caráter de antecipação, aprofundamento ou revisão de conteúdo, foram priorizados pelos alunos em detrimento dos aplicativos de uso contínuo. Apesar de serem de grande valia para a expansão do vocabulário em língua estrangeira, Duolingo e Memrise, indicados respectivamente para o $1^{\circ}$ e $3^{\circ}$ ano do ensino 
médio, foram preteridos pelos alunos, principalmente por demandarem dedicação diária para execução de seus breves exercícios.

Quanto à avaliação que os estudantes fizeram acerca dos recursos explorados online, ela foi, em geral, positiva. Os alunos enfatizaram diversos benefícios citados por Berking e Gallagher (2016), como funções dos softwares de gerenciamento da aprendizagem. As funcionalidades que mais emergiram dos dados foram: interação, distribuição e armazenamento de registros. A função de interação foi relacionada à praticidade de se comunicar com a professora a partir do recurso de chat do LMS em comparação ao uso de e-mail da turma, um recurso on-line utilizado por outros professores. Já a distribuição de conteúdo, como trabalhos escolares, foi avaliada como simples e intuitiva, enquanto o armazenamento de registros foi elogiado por conter um resumo das matérias da disciplina.

Uma estratégia pedagógica mencionada pelos próprios alunos que poderia potencializar o ensino híbrido, subvertendo o esquecimento mencionado por muitos deles, seria a adoção de um grupo de WhatsApp com cada turma. A principal função deste grupo seria suplementar o uso do AVA, promovendo uma maior aproximação entre alunos e docente por se tratar de um aplicativo familiar e de uso recorrente. No entanto, esta estratégia precisa ser cuidadosamente estudada para não sobrecarregar o professor nem ferir questões éticas com a utilização de contatos pessoais, o que pode atrapalhar a relação professor-aluno.

Por fim, dessa pesquisa já nascem novas ideias que poderão ser incorporadas a um replanejamento pedagógico, tais como a adoção de um grupo de WhatsApp da turma e a utilização dos aplicativos de uso contínuo somente como opção de estudo informal. Mesmo necessitando de alguns ajustes, é possível concluir que a experiência de introdução do ensino híbrido como complementar as aulas de inglês no ensino médio técnico foi proveitosa, uma vez que nenhuma avaliação negativa foi remetida ao uso do AVA, somente aos aplicativos de uso contínuo.

\section{Referências}

ANGROSINO, M. V. Recontextualizing Observation: Ethnography, Pedagogy, and the Prospects for a Progressive Political Agenda. In N. K. Denzin \& Y. S. Lincoln (Eds.), The Sage handbook of qualitative research (pp. 729-745). Sage Publications Ltd, 2005. 
BACICH, L.; MORAN, J. Aprender e ensinar com foco na educação híbrida. Revista Pátio, [s. I.], n. 25, p. 45-47, jun. 2015. Disponível em:

http://www2.eca.usp.br/moran/wp-content/uploads/2015/07/hibrida.pdf. Acesso em: 07 jan. 2019.

BARDIN, L. Análise de conteúdo. Lisboa: Edições 70, 2009.

BERKING, P.; GALLAGHER, S. Choosing a learning management system. Advanced Distributed Learning (ADL), 16 Dec. 2016. Disponível em: www.adlnet.gov/wpcontent/uploads/2013/05/Choosing_an_LMS.pdf. Acesso em: 14 jan. 2019.

DENZIN, N.; LINCOLN, Y. A disciplina e a prática da pesquisa qualitativa. In: DENZIN, N.; LINCOLN, Y. (org.). O planejamento da pesquisa qualitativa: teorias e abordagens. Porto Alegre: Artmed, 2006. p. 15-41.

DILLENBOURG, P.; SCHNEIDER, D.; SYNTEKA, P. Virtual Learning environments. In: HELLENIC CONFERENCE "INFORMATION \& COMMUNICATION TECHNOLOGIES IN EDUCATION", 3., 2002, Grécia. Proceedings [...]. Grécia: Kastaniotis Editions, 2002. p. 3-18.

GARRIDO, S. M. L. Planejamento. Curitiba: IESDE Brasil, 2009.

GEBRAN, M. P. Tecnologias educacionais. Curitiba: IESDE Brasil, 2009.

HARRIS, L. R. A Phenomenographic investigation of teacher conceptions of student engagement in learning. Australian Educational Researcher, [s. I.], v. 35, n. 1, p. 5779, 2008. Disponível em: http://www.eric.ed.gov/ERICWebPortal/contentdelivery/servlet/ERICServlet?accno=

EJ793463. Acesso em: 22 jun. 2019.

MORAN, J. Educação híbrida: um conceito-chave para a educação, hoje. In: BACICH, L.; NETO, A.; TREVISANI, F. (org.). Ensino híbrido: personalização e tecnologia na educação. Porto Alegre: Penso, 2015.

SANTAELLA, L. A aprendizagem ubíqua substitui a educação formal? Revista de Computação e Tecnologia, São Paulo, v. 2, n. 1, p. 1-6, 2010. Disponível em: http://revistas.pucsp.br/index.php/ReCET/issue/view/223/showToc. Acesso em 22 jun. 2019.

VYGOTSKY, L. S. Interação entre aprendizado e desenvolvimento. In: VYGOTSKY, L. S. A formação social da mente: o desenvolvimento dos processos psicológicos superiores. São Paulo: Martins Fontes, 1999.

YIN, R. K. Case study research: design and methods. London: SAGE, 2009. 